\title{
O conceito Cultura Tecnológica e um estudo no meio educacional
}

\section{The concept Technological Culture and a study in the educational environment}

\author{
Zulmira Medeiros ${ }^{1}$ \\ Paulo Cezar Santos Ventura ${ }^{2}$
}

\section{Resumo}

Neste artigo apresenta-se, inicialmente, um breve estudo acerca das evoluções sociais e da sua relação com a tecnologia. Em seguida, a partir do conceito de cultura, trata-se das variações culturais no âmbito tecnológico, buscando-se analisar a relação entre o homem e a tecnologia como um processo de socialização e de apropriação. Num segundo momento, são apresentados alguns resultados de um estudo de caso que acompanhou a criação, implantação e utilização do portal da Rede Municipal de Ensino de São Paulo. Dentre os objetivos deste estudo destaca-se o interesse por se compreender a percepção do educador acerca desse espaço. Confirmando a hipótese inicial, percebeu-se que a utilização do portal de forma colaborativa e produtiva implica um processo de apropriação cultural.

Palavras-chave: cultura, tecnologia, cultura tecnológica.

\begin{abstract}
This paper presents, initially, a briefing study concerning the social evolutions and its relation with technology. After that, from the culture concept, cultural variations in the technological scope are discussed, aiming the analysis of the relation between man and technology as a socialization and appropriation process. Some results of a case study that followed the creation, implantation and use of the portal of São Paulo Municipal Education are presented. Amongst the objectives of this study it is distinguished the interest for the understanding of the educator perception about this space. Confirming the initial hypothesis, it is assumed that the use of the portal in a collaborative and productive way implies in a cultural appropriation process.
\end{abstract}

Key words: culture, technology, technological culture.

\footnotetext{
${ }^{1}$ Pedagoga, Mestre em Educação Tecnológica pelo CEFET-MG.zulmira_medeiros@yahoo.com.br

${ }^{2}$ Doutor em Ciências da Comunicação da Informação pela Université de Bourgogne. pcventura@gmail.com
} 


\section{Introdução}

"A natureza dos homens é a mesma, são os seus hábitos que os mantêm separados”.

Essas palavras, ditas por Confúcio quatro séculos antes de Cristo (LARAIA, 2001), mostram-se ainda muito atuais. Os hábitos tanto podem segregar grupos, cada um com suas próprias regras, costumes e mecanismos de controle, quanto ser o elo entre indivíduos de um mesmo grupo, mantendo sua coesão e cumplicidade. Laraia (2001) conclui que os hábitos, muito mais que os aspectos biológicos ou ambientais, definem a cultura dos grupos sociais.

Entende-se por cultura o complexo dos padrões de comportamento, crenças, valores e hábitos transmitidos coletivamente e característicos de uma sociedade (FERREIRA, 1999). As transformações por que passa essa sociedade produzem mudanças nos seus sistemas de produção, nas relações sociais e, por conseguinte, podem provocar conflitos e o surgimento de novos modelos culturais. Essas mudanças culturais muitas vezes representam as próprias adaptações dos indivíduos ao seu meio. Ainda segundo Laraia (2001), a tecnologia é um dos principais fatores desencadeadores de processos adaptativos, a partir dos quais outras mudanças adaptativas se ramificam.

Não é necessário muito esforço para percebermos a rapidez com que as mudanças de cunho tecnológico vêm ocorrendo em nossa sociedade nas últimas décadas. Expressões como 'sociedade da informação', 'sociedade tecnológica' e 'sociedade do conhecimento' têm sido utilizadas para caracterizar a sociedade pósindustrial. Uma sociedade que exige de seus indivíduos uma nova maneira de ser, de pensar, de produzir, de aprender, de conviver. Moran (2000) chega a propor o conceito de 'sociedade interconectada', em que todos estão reaprendendo a se comunicar, a integrar o humano e o tecnológico, a integrar o individual, o grupal e o social.

Também a cultura dessa sociedade vem passando por mudanças significativas. Em todo momento são necessárias novas formas de comportamento e de relacionamento entre os indivíduos para que possam atuar em uma realidade que muda constantemente. A tecnologia tem eliminado progressivamente as barreiras físicas e temporais, facilitando a comunicação e o acesso às informações, potencializando as adaptações, as transformações e as reestruturações culturais.

Uma dessas adaptações culturais, aqui denominada cultura tecnológica, refere-se aos novos comportamentos advindos da utilização dos recursos da tecnologia, 
principalmente da tecnologia da comunicação e da informação. Assim como muitos aspectos sociais mudaram em função dessa evolução tecnológica, também os valores e concepções passam por mudanças.

\section{Sociedade}

[...] ao transformar, ao longo do tempo, as formas de produzir e reproduzir os meios de sua própria sobrevivência, o ser humano modificou também suas relações humanas e com a natureza. As tecnologias que criou - desde a roda até o computador - geraram transformações na maneira de se comunicar, produzindo meios de comunicação cada vez mais complexos (SAMPAIO e LEITE, 1999, p. 13).

É possível estabelecer uma classificação dos grandes períodos vividos pelo homem baseada nas características do modo de produção dominante em cada época (PENIN, 2001). O primeiro desses períodos, chamado de sociedade agrária, teve seu principal modo de produção baseado na agricultura de subsistência. Sem dispor de recursos tecnológicos sofisticados, os homens plantavam e colhiam tendo como referência os ciclos da natureza - o dia e a noite e as estações do ano. Tornar-se apto ao trabalho nessa sociedade era uma tarefa que se atingia em pouco tempo e o conhecimento adquirido seria utilizado durante toda a vida. $\mathrm{O}$ maior indicador de riquezas era a propriedade agrária. A comunicação se dava, normalmente, de forma direta, presencial. Os que tinham acesso à leitura e à escrita podiam também fazer uso desse recurso para se comunicar.

Com a Revolução Industrial, a partir da segunda metade do século XVIII, iniciase o segundo período, denominado de sociedade industrial. O homem se distancia da natureza e imerge no mundo das máquinas. Tornar-se apto ao trabalho demanda mais tempo do que na sociedade agrária, e o trabalhador necessita ser mais e mais especializado. O indicador de riqueza na sociedade industrial é a detenção dos meios de produção, o capital e o lucro. Foi na sociedade industrial que os meios de comunicação passaram a contar com o telégrafo, o rádio, o telefone, a televisão e, ainda, com um considerável crescimento nos meios de transporte, o que impulsionou o desenvolvimento da correspondência postal.

Na segunda metade do século XX inicia-se o terceiro período, a sociedade tecnológica, caracterizada principalmente pelas mudanças mais recentes nas tecnologias e nos meios de comunicação. O fluxo de informações é intenso, o que faz com que o saber adquirido torne-se obsoleto - não raro, por diversas vezes - durante a trajetória profissional e, por isso, o trabalhador precisa estar em constante processo de formação. 
Nessa sociedade, o principal bem é o conhecimento. Daí alguns autores denominarem esse período de sociedade do conhecimento ou sociedade da informação ${ }^{i}$.

A utilização do termo "sociedade tecnológica" não significa que a relação do homem com a tecnologia surgiu nesse período. Kenski (2003) lembra que a tecnologia está presente em todos os lugares e ações do nosso cotidiano - papel, caneta, pratos, talheres, medicamentos etc. Tecnologia seria, pois, o "conjunto de conhecimentos e princípios científicos que se aplicam ao planejamento, à construção e à utilização de um equipamento em um determinado tipo de atividade" (p. 18), enquanto a técnica seria a maneira, jeito ou habilidade de lidar com cada tipo de tecnologia para realizar determinada ação. Por isso, não somente a atualidade deve ser chamada de período tecnológico, pois cada período da história da humanidade é caracterizado por determinados recursos tecnológicos.

Essa classificação em três grandes momentos não deve levar à conclusão de que o processo se deu de forma linear, com a substituição de um determinado modo de produção pelo outro, pois "o processo de desenvolvimento de uma civilização é claramente acumulativo: conserva-se o antigo, apesar da aquisição do novo" (LARAIA, 2001, p. 40). Ocorreu que cada modo de produção continuou a existir, mas fortemente influenciado pelo(s) seguinte(s). É o que se tem na atualidade: uma agricultura que se utiliza da indústria e das mais recentes tecnologias e uma indústria que, por sua vez, se torna, a cada dia, mais e mais sofisticada tecnologicamente.

Lemos (2004, p. 19) considera que "as novas tecnologias de comunicação e informação estão reconfigurando os espaços urbanos, bem como as práticas sociais destes mesmos espaços". Essas evoluções sociais são acompanhadas por mudanças também culturais. Cada momento e cada espaço social são repletos de tendências culturais que influenciam significativamente as atitudes e os comportamentos dos indivíduos e dos grupos.

A sociedade da informação coloca ao alcance das pessoas espaços e formas de interação nunca antes imaginados pela maioria de seus usuários. Isso exige uma maneira inteligente de se utilizar os novos meios e instrumentos de comunicação e informação (CEBRIÁN, 1999). Daí o nosso interesse em discutir acerca de como está se desenvolvendo a nossa sociedade e como aproveitar as possibilidades oferecidas por esses espaços de interação. 


\section{Cultura}

A cultura é como uma lente através da qual o homem vê o mundo. Homens de culturas diferentes usam lentes diversas e, portanto, têm visões desencontradas das coisas (BENEDICT, 1972 apud LARAIA, 2001, p. 67).

Como dito anteriormente, segundo Ferreira (1999) cultura são os padrões de comportamento, crenças, valores e hábitos transmitidos coletivamente e característicos de uma sociedade.

O conceito de cultura construiu-se através da história da própria humanidade. A palavra veio do latim medieval colere, que significa cultivo, cuidado, mais relacionado à agricultura, pois, na Roma antiga, cultivar a terra era uma atividade enobrecedora. Mais tarde, o significado de cultura foi estendido, pelos pensadores romanos, ao cuidado com as crianças e com a sua educação, ao refinamento intelectual. A partir do século XVIII, o conceito de cultura foi relacionado ao conceito de civilização - o homem civilizado era o homem culto. No século XX surgiu a concepção de diversidade cultural, e a cultura passou a ser vista como uma dimensão social, um conjunto de regras comuns a um grupo (GOHN, 2001).

$\mathrm{Na}$ sociedade contemporânea, o estudo da cultura ganhou abordagens diferenciadas: cultura popular ${ }^{\mathrm{ii}}$, cultura de massa ${ }^{\mathrm{iii}}$, cultura nacional $^{\mathrm{iv}}$, cultura política $^{\mathrm{v}} \mathrm{e}$, principalmente, a partir das últimas décadas do século $\mathrm{XX}$, o advento das novas tecnologias da informação e comunicação, ou tecnologias digitais, fez emergir expressões como cultura da mídia, cultura tecnológica, cultura virtual e cibercultura.

Por vezes, o conceito de cultura é associado ao nível de escolaridade; às artes, como o cinema, a pintura; às tradições de um povo, como o folclore, os mitos; às etapas históricas, como a cultura medieval, a cultura moderna; à forma de vestir ou à comida, como a cultura francesa, a cultura árabe. Laraia (2001) desenvolve o seu trabalho no intuito de demonstrar que o homem é resultado do meio cultural em que foi socializado, comprovando que nem o determinismo biológico nem o determinismo geográfico são suficientes para explicar o comportamento humano.

As ciências sociais consideram a cultura como o conjunto de aspectos que caracterizam o modo de vida de um grupo, de uma comunidade ou de uma sociedade. Aspectos esses que são mais fruto de uma aprendizagem informal do que de uma transmissão institucionalizada (FORQUIM, 1993).

Santos (1996), em sua abordagem de cultura como "aspectos da realidade social", afirma que "cultura diz respeito à humanidade como um todo e ao mesmo 
tempo a cada um dos povos, nações, sociedades e grupos humanos" (p. 8). Sob esse prisma, admite-se a possibilidade de identificar variações culturais dentro de uma mesma sociedade, ou seja, permite-se a análise de grupos de indivíduos que se diferenciam dos demais por seus hábitos e comportamentos sociais. São justamente essas divergências que mantém o dinamismo das sociedades e das suas culturas.

Dessa forma, não se limita o conceito de cultura para caracterizar o que é erudito dentro de um povo, mas também para se referir a manifestações mais localizadas em grupos menores. 'Localizadas' não quer dizer 'isoladas', pois nenhuma cultura é autônoma, ao contrário, mantém relações complexas com a sociedade de que faz parte. "Ela é produto dessa sociedade, mas também ajuda a produzi-la" (SANTOS, 1996, p. $65)$.

Nota-se que é consenso entre os autores citados que a cultura é algo dinâmico, intrinsecamente relacionado às mudanças sociais. A cultura é vista por eles como produto coletivo da vida humana, uma dimensão do processo social em constante mudança. Santos conclui que:

O estudo da cultura exige que consideremos a transformação constante por que passam as sociedades, uma transformação de suas características e das relações entre categorias, grupos e classes sociais no seu interior. [...] Cultura é uma dimensão do processo social, da vida em sociedade (SANTOS, 1996, p. 44).

Gohn (2001) compartilha dessa concepção ao afirmar que, nas pesquisas sociológicas, "a cultura sempre aparece associada a processos de mudança e transformação social, como mola propulsora de mudanças sociais" (p. 30). Ao se falar em mudanças sociais e culturais, é pertinente sinalizar para as duas maneiras em que podem se apresentar. Algumas mudanças são resultantes de fatores externos ou do contato com outros grupos sociais e culturais. Outras, conforme dito anteriormente, são produtos da dinâmica interna da própria sociedade, grupo ou instituição, pois, no dia-adia, os sujeitos vão se formando e também produzindo novos comportamentos e, assim, recriando a cultura geral, numa via de mão dupla.

Concluímos, portanto, que não se pode estudar a cultura como algo pronto, estático, pois, ao mesmo tempo, ela é condicionada e condiciona uma sociedade que, por sua vez, está em constante transformação. Tampouco acreditamos que a cultura é expressa somente como uma representação mais ampla da sociedade, mas que pode também ser analisada a partir de agrupamentos e suas diversidades culturais. Sob esse 
ponto de vista, consideramos interessante uma abordagem mais específica acerca dos aspectos culturais inerentes à relação entre o homem e as tecnologias digitais.

\section{Cultura tecnológica}

A ciência e a tecnologia são aspectos da cultura por causa do impacto direto que têm nos destinos das sociedades atuais (SANTOS, 1996, p. 77).

Em um trabalho realizado recentemente no curso de Mestrado em Educação Tecnológica do CEFET-MG, em que Redá, Alves e Tonani (2006) pesquisaram sobre a temática cultura tecnológica entre os professores do curso, concluiu-se que "a cultura e a tecnologia dificilmente terão uma definição pronta e acabada, sempre que pensarmos nesses termos, acrescentar-lhes-emos novos fatores" (p. 15). Isso porque as próprias evoluções sociais imprimem novo significado às coisas, fazendo com que novas definições sejam concebidas, confirmando o dinamismo conceitual descrito no item anterior.

Segundo Castells (1999), o desenvolvimento tecnológico e as transformações das sociedades estão intimamente relacionados, embora "a tecnologia não determine a sociedade e nem a sociedade escreva o curso da transformação tecnológica" (p. 25), pois existem muitos outros fatores que determinam o resultado final. Essa abordagem confirma-se nas palavras de Rodrigues:

\footnotetext{
A tecnologia é o pano de fundo, o próprio quadro referencial, no qual todos os outros fenômenos sociais ocorrem. Ela molda nossa mentalidade, nossa linguagem, nossa maneira de estruturar o pensamento, inclusive a nossa maneira de valorar. [...] Por outro lado, toda cultura tem seus valores arraigados. Esses valores são questionados na medida em que a sociedade tecnológica evolui (RODRIGUES, 2001, p. 76-77).
}

Lévy (1999) prefere não tratar do impacto das tecnologias sobre a sociedade e a cultura, pois, segundo ele, isso enfoca uma distinção entre essas três entidades. Esse autor defende tal distinção apenas no plano conceitual. Para ele, as tecnologias não determinam a cultura, mas a condicionam. A diferença, segundo ele, é que condicionar significa oferecer possibilidades que podem ser aproveitadas ou não.

Segundo Benakouche (1995), o sentido do termo 'impacto', nesse caso, pressupõe que a sociedade possa ser passivamente atingida por inovações que lhe são externas. Concordando com Lévy, Benakouche acredita que não se pode separar tecnologia e sociedade dessa forma, atribuindo à primeira um aspecto não social, uma 
autonomia que ela não possui, pois é fruto das demandas sociais. A autora prefere o uso do termo 'implicações' para tratar das relações entre tecnologia e sociedade, por acreditar ser essa uma relação de reciprocidade, de interação. Nota-se que é comum, entre esses autores, que não se deve tratar a tecnologia como determinante das mudanças sociais, até porque isso significaria dar à tecnologia um 'poder' que não lhe é característico.

Superando a idéia de que a tecnologia seja atualmente responsável por toda e qualquer característica social e cultural, é necessário, no entanto, reconhecermos que ela (a tecnologia) constitui-se num dos campos adaptativos da cultura, a partir do qual outras mudanças adaptativas e culturais se realizam. Como exemplo, temos os meios de comunicação, que nos últimos anos passaram por uma verdadeira revolução tecnológica, gerando novas relações sociais, transformando a cultura e colocando novos desafios e necessidades aos indivíduos, principalmente no que concerne aos conceitos de tempo e de espaço (LARAIA, 2001).

Lévy (1999) faz uma comparação entre os meios de comunicação: o correio e o telefone são exemplos de dispositivos comunicacionais 'um para um'; o rádio e a televisão são exemplos de dispositivos comunicacionais 'um para todos'. Já a internet seria um exemplo de dispositivo comunicacional 'todos para todos'. Segundo esse autor, os dispositivos comunicacionais e informacionais são os maiores produtores de mudanças culturais, pois definem a relação entre os participantes e os meios de comunicação e informação.

Desse modo, vemos que a tecnologia se apresenta como uma peça importante na constituição cultural da sociedade. Assim como cada realidade cultural tem sua lógica interna própria, com o mundo tecnológico não é diferente. É preciso que o sujeito saiba relacionar a variedade de procedimentos culturais com os contextos em que são produzidos para que as suas práticas e concepções lhe façam sentido, evitando comportamentos preconceituosos, e para que lhe seja possível articular-se nesse contexto.

No entanto, sabemos que a participação de um indivíduo em sua cultura é sempre limitada, conforme afirma Marion Levy:

Nenhum sistema de socialização é idealmente perfeito, em nenhuma sociedade são todos os indivíduos igualmente bem socializados, e ninguém é perfeitamente socializado. Um indivíduo não pode ser igualmente familiarizado com todos os aspectos de uma sociedade; pelo contrário, ele 
pode permanecer completamente ignorante a respeito de alguns aspectos (LEVY, Marion, 1952 apud LARAIA, 2001, p. 82).

Laraia (2001) ressalta que é necessário, entretanto, que exista um mínimo de participação do indivíduo no contexto cultural a fim de permitir a sua convivência com os demais membros daquela sociedade. Nesse sentido, Lévy (1999) concorda que "para integrar-se a uma comunidade virtual, é preciso conhecer seus membros e é preciso que eles o reconheçam como um dos seus" (p.68), o que implica um processo de socialização e aculturação. Esse é o motivo pelo qual consideramos a importância do universo cultural relacionado às questões tecnológicas na sociedade atual.

Acreditamos, assim como Freitas (2004), que a aproximação entre o homem e o objeto técnico produz uma relação de familiaridade com a tecnologia. Segundo a autora, assim como a cultura rege as relações do homem com a sociedade, a cultura tecnológica se faz necessária justamente para facilitar o processo de socialização do homem no mundo atual.

Graells (2000) ressalta as mudanças culturais advindas da relação entre o homem e a tecnologia:

\begin{abstract}
Na sociedade da informação surge uma nova forma de cultura, a cultura da tela que, como dizia Arenas (1991), se sobrepõe à cultura do contato pessoal e à cultura do livro. Além disso, junto ao mundo físico, real, com o qual interagimos, agora dispomos também do ciberespaço, mundo virtual, que multiplica e facilita nossas possibilidades de acesso à informação e de comunicação com os outros (GRAELLS, 2000, p. 4) [Tradução nossa] ${ }^{\mathrm{vi}}$.
\end{abstract}

$\mathrm{O}$ autor fala, de modo geral, de uma cultura digital (cultura da tela) potencializada pelas tecnologias digitais e, de um modo particular, da cultura virtual presente no ciberespaço.

Segundo Lévy (1999), o ciberespaço é o novo meio de interação e comunicação possibilitado pela internet. Envolve não só a estrutura tecnológica, mas a amplitude de informações nele contida e os seres humanos que utilizam esse espaço. Está intrínseco nesse meio a cibercultura, que, segundo o autor, é o conjunto de técnicas, atitudes, valores e formas de pensamento que se desenvolvem juntamente com o ciberespaço. Lemos vê a cibercultura como resultante dos contatos entre o homem atual e as tecnologias digitais: 
informáticas e as mídias de comunicação. Este conjunto de atitudes é produto de um movimento sociocultural para domesticar e humanizar as novas tecnologias. Conforme minha hipótese, ela é a expressão cultural do encontro entre a 'sociedade pós-moderna' e as novas tecnologias baseadas na microeletrônica (LEMOS, 1994, p. 1) [Tradução nossa] $]^{\text {vii }}$.

Castells (1999), embora acredite que a sociedade em rede possua uma dimensão cultural própria, não vê a cultura virtual como um conjunto de valores, no sentido tradicional do termo, pois, segundo ele, a própria estrutura e diversidade das redes rejeitam esse modelo de cultura unificadora. Ao contrário, para ele, a cultura virtual seria uma cultura do efêmero, multifacetada. Percebe-se que essa é uma forma distinta de se definir o termo, pois o autor trata da impossibilidade de se caracterizar a amplitude de usuários do ciberespaço, cada um em sua diversidade social e cultural.

Nesse ponto, concordamos tanto com a visão de Lévy (1999) e Lemos (1994) quanto com a de Castells (1999), mas, neste trabalho, interessa-nos também o conceito de cultura tecnológica, utilizado por Freitas (2004), por priorizarmos o estudo de um modelo cultural próprio da sociedade tecnológica e por entendermos que a cultura tecnológica caracteriza uma abordagem mais ampla que, de certa forma, precede a cibercultura ou a cultura virtual.

Falar em cultura tecnológica implica dizer que as evoluções tecnológicas vividas pela sociedade atual não se restringem apenas ao uso de novos equipamentos e produtos. Muito mais que isso, implica a modificação de comportamentos, de certa forma, impondo-se à cultura existente e transformando indivíduos, grupos e sociedade (KENSKI, 2003).

Acreditamos que a relação entre o homem e a tecnologia envolve um processo de apropriação da cultura tecnológica, que influencia diretamente a sua atuação na sociedade em rede. Em seu trabalho, Redá et al (2006), percebeu que a maioria dos professores, além de se sentirem inseridos em uma cultura tecnológica, afirmam que tal processo de aculturação é de suma importância em seu meio social.

Consideramos, assim, o conceito de cultura tecnológica como um conjunto complexo de valores, comportamentos, linguagens, hábitos e relações sociais característicos da sociedade tecnológica atual, delineada a partir das mais recentes inovações nos meios de comunicação e informação. E concluímos que a importância da cultura tecnológica está relacionada com a possibilidade de o indivíduo agir socialmente, a partir de um saber tecnológico do qual ele se apropria e desenvolve a sua identidade, tornando-se um cidadão tecnologicamente competente. 


\section{Um estudo no meio educacional}

No período de novembro de 2003 a março de 2005, realizamos um estudo de caso na Rede Municipal de Ensino de São Paulo, durante o processo de criação, desenvolvimento e implantação de um portal na internet.

O projeto de desenvolvimento desse portal, uma iniciativa da Secretaria Municipal de Educação, buscou disponibilizar a toda a comunidade escolar, a partir de um mesmo ambiente na web, um sistema de gestão escolar (cadastro e controle de dados das escolas, dos servidores e dos alunos) e um sistema colaborativo (sites das escolas com notícias, calendário de eventos, fóruns, chats, artigos, aulas, projetos etc.).

Dentre os objetivos desse estudo de caso, destacamos o interesse por conhecer a percepção do educador quanto ao uso da internet como um novo espaço de interação com seus pares, e se o uso desse espaço promove a inserção dessas pessoas no novo modelo cultural proporcionado pelas tecnologias digitais.

Desse modo, por meio de observações, levantamentos, questionários e entrevistas, nossa investigação concentrou-se num grupo de 796 educadores. A escolha por tais sujeitos justifica-se por serem as pessoas que se relacionaram diretamente com o projeto do portal, desde a etapa de especificação das funcionalidades que o iriam compor (atividade essa realizada junto à equipe técnica). Esses educadores participaram também da primeira etapa de capacitação no módulo de gerenciamento dos sites, ou seja, tinham acesso aos recursos de inclusão e publicação de conteúdos. Desse grupo, 4 educadores foram designados pela Secretaria de Educação para compor o Grupo Gestor do Portal, com dedicação exclusiva para tal fim. Os demais compunham as equipes de trabalho com o portal em cada regional de ensino e em cada escola (no mínimo 2 pessoas por unidade).

$\mathrm{Na}$ análise dos dados, utilizamos uma abordagem predominantemente qualitativa, por meio de categorias criadas a partir das respostas dadas aos questionários e às entrevistas, associadas aos dados coletados nas observações e nos levantamentos. A seguir, apresentamos algumas das conclusões do trabalho, especificamente aquelas relacionadas à temática cultura tecnológica.

\section{O educador e o portal}

Uma das questões iniciais da pesquisa, sobre a forma como o educador vê a internet como um novo espaço de interação com seus pares, foi ampliada, incluindo também a forma como ele vê a interação com a comunidade escolar. Notamos que a 
receptividade do educador foi bastante positiva, demonstrando uma percepção das possibilidades que se abriram com a implantação e a utilização do portal, como pode ser visto em alguns depoimentos:

\footnotetext{
Acho que abrirá espaço para participação da comunidade escolar, pois mesmo que não tenham acesso como autores, poderão contribuir através de sugestões, numa gestão democrática (E-201) ${ }^{\text {viii. }}$.

É uma nova forma de comunicação que privilegia a importância do registro. Em nossas escolas acontecem muitas coisas boas, mas estas experiências ficam só dentro da unidade. Com o portal poderemos ampliar os horizontes (E-494).
}

Ao valorizar aspectos como a divulgação dos trabalhos das escolas, a troca de informações e experiências entre educadores e o acesso da comunidade, eles concordaram com o que Moran (2000) acredita ser uma necessidade da educação contemporânea: a de se tornar um processo de comunicação participativo, interativo e vivencial, entre toda a comunidade escolar - administradores, funcionários, professores, alunos e familiares.

Os educadores demonstraram ainda perceber as circunstâncias criadas pelas tecnologias da informação e comunicação, e que permitem "a formação de redes de pessoas interagindo via internet" (VALENTE, 2002, p. 34) (categoria presente em $50,9 \%$ das respostas), e viram o portal como um instrumento potencializador da democratização do acesso e da participação da comunidade (categoria presente em $20,4 \%$ das respostas).

\section{A apropriação da tecnologia}

Outras duas questões da pesquisa tratavam das mudanças que ocorrem nas relações entre as pessoas de uma mesma comunidade educacional, a partir do uso da internet como um novo espaço de interação, e se o uso desse espaço promove a inserção dessas pessoas no novo modelo cultural proporcionado pelas tecnologias digitais. Essas temáticas, embora não pudessem ser tratadas tendo-se como base a utilização efetiva do portal pelos usuários, dado o curto período de tempo em que tal utilização pôde ser observada, esteve muito presente nas falas dos educadores e no referencial teórico do trabalho:

É muito interessante saber criar página. Nunca pensei que seria capaz, pois considerava algo muito difícil de aprender. Estou feliz por ter conseguido aprender alguns recursos para tal fim (E-577). 
Quando Freitas (2004) lembra que a aproximação com o objeto técnico produz uma relação de familiaridade com a tecnologia, quando Kenski (2003) considera ser tal familiaridade o primeiro passo para a apropriação da tecnologia e, ainda, quando Doron e Parot (2001) afirmam que o processo de apropriação é intrínseco às interações sociais, conclui-se que o uso da internet como espaço de interação em uma comunidade escolar aproxima seus usuários da tecnologia. Acreditamos, desse modo, que a própria utilização do portal pode funcionar como um mecanismo de difusão e de apropriação da técnica, fazendo com que a cultura tecnológica se fortaleça entre os usuários do portal.

Os educadores, em seus depoimentos, também valorizaram muito as possibilidades de inclusão digital que se abriram a toda a comunidade escolar a partir da implantação de um objeto técnico que pode ser acessível a educadores, alunos e familiares:

É praticamente um projeto em que, de uma forma ou de outra, todos os segmentos da escola estarão envolvidos (E-497).

Possibilita que todos tenham acesso às informações e aos trabalhos desenvolvidos nas escolas, mesmo aqueles que não possuem computador, pois poderão acessar pelos telecentros (E-410).

Podemos dizer que o portal teria uma função implícita de ser facilitador da inclusão digital e da apropriação da cultura tecnológica. Conseqüentemente, a socialização e a capacidade de atuação desses indivíduos no meio seriam beneficiadas.

Acerca das influências do portal sobre as relações entre os educadores, pudemos concluir, a partir dos depoimentos presentes nas respostas aos questionários e do diálogo que se observou em aplicativos como o fórum, que a comunicação e a troca entre os educadores são ações significativamente ampliadas e reforçadas pelo novo dispositivo comunicacional (LEVY, 1999), sem a pretensão de substituir os encontros presenciais, mas como um meio de estimular, registrar e valorizar a participação de todos:

O mais positivo do projeto é o intercâmbio que haverá entre as escolas, entre coordenadorias e mesmo entre professores como troca de experiências (E107).

[...] o relacionamento entre professores e alunos e entre escola e comunidade atingirá um novo patamar (E-190). 


\section{A cultura e a tecnologia}

Uma das questões centrais da pesquisa tratava da forma como os artefatos tecnológicos envolvem aspectos culturais. É interessante lembrar a comparação entre a cultura e uma lente (BENEDICT, 1972 apud LARAIA, 2001), através da qual os indivíduos vêem o mundo. Percebemos que o portal teve um bom nível de aceitação entre os educadores principalmente pelo fato de já haver entre eles uma cultura anterior que demandava a presença das escolas na internet, por meio de seus sites (11\% das escolas já possuía um site por iniciativa própria e $72 \%$ desejava ter um site). Da mesma forma, o número ainda pequeno de usuários cadastrados e de acessos semanais pode ser justificado pela falta da cultura tecnológica em uma significativa parcela de integrantes da rede de ensino:

O fato de ainda não fazer parte da cultura da RME-SP fez com que muitos não incorporassem a construção e alimentação do portal no cotidiano de suas atividades (GG2).

Outro aspecto importante, do qual nos fala Schlithler (2003), é que um dos maiores desafios para uma organização em rede, e aqui se enquadra a rede sociotécnica, é a mudança cultural que ela demanda. Notamos em campo, em alguns momentos, certa tendência por se transportar para o novo espaço as características já enraizadas na cultura organizacional. Um exemplo disso foi responsabilizar os professores de informática pela atualização do site de sua unidade:

Fico pensando na escola. O POIE ${ }^{\text {ix }}$ trabalha boa parte de seu tempo com os alunos, outra parte capacita os professores. Não sei bem como este trabalho na construção e alimentação do portal se dará (E-018).

Um exemplo contrário foi a formação do Grupo Gestor do Portal, composto por educadores com dedicação exclusiva às atividades relacionadas ao projeto, cuja finalidade era ser uma equipe incentivadora, orientadora, mas não responsável por todas as publicações do portal, já que a proposta era a de instigar a participação de todos.

Acreditamos que, para ser caracterizado realmente como um ambiente colaborativo, o portal não pode ser entendido como um departamento dentro da instituição, ao qual apenas um grupo restrito possui permissão para inclusão e publicação de conteúdos. Ao contrário, deve permear todos os processos e setores, favorecendo a participação e a colaboração. Por isso, concordamos com os educadores 
quando, em seus depoimentos, alertaram para a necessidade de se rever as estruturas e responsabilidades:

Que não seja encarado como atividade exclusiva de POIE, e se o for, que haja uma portaria regulamentando as horas a serem dedicadas para tal fim (E114).

O portal não pode ser tarefa de alguns, suas funcionalidades e conteúdos devem representar a identidade da instituição, e não a de um grupo. Daí a necessidade de participação dos usuários no envio de sugestões de conteúdos (artigos, referências, aulas, projetos etc.) a serem publicados. Apesar de essa constatação estar presente nas palavras da Secretária de Educação e nos depoimentos dos educadores, a participação dos usuários nos primeiros meses de utilização do portal foi considerada pequena diante do tamanho da rede de ensino em questão:

[...] grande parte do público alvo (educadores em geral, alunos e familiares) ainda desconhecem o portal. Acredito que quando essas pessoas souberem da existência dessa ferramenta eles mesmos cobrarão a construção e atualização do site de sua unidade, sendo co-participantes (GG2).

Sabemos que muitas outras variáveis influenciam, em maior ou menor grau, a utilização desse portal pelos educadores, tais como o tempo necessário para atualização dos sites e as condições técnicas disponíveis (acesso de má qualidade ou falta de acesso à internet em algumas unidades), conforme eles mesmos explicitaram em suas falas.

Há que se ter a compreensão de que o portal não é uma analogia e nem uma substituição do território e seus processos (LÉVY, 1999), mas um espaço que o complementa, que o amplia, que coloca em sinergia as contribuições de todos os seus usuários (LEMOS, 2004). Consideramos, entretanto, que tal processo demanda de todos os envolvidos (gestores, educadores, comunidade) uma mudança atitudinal, uma mudança cultural, que só será conseguida após um tempo de utilização e compreensão deste novo ambiente. Retomando o conceito de cultura tecnológica - um conjunto complexo de valores, comportamentos, linguagens, hábitos e relações sociais característicos da sociedade tecnológica - e relacionando-o com o que pudemos observar em campo, concluímos que a aquisição desse saber tecnológico envolve, pois, um processo de apropriação cultural. 


\section{Referências}

BENAKOUCHE, Tâmara. Fatores Sociais e Culturais na Utilização Diferenciada de Redes Eletrônicas no Brasil: notas para discussão. Anais do Seminário Preparatório sobre aspectos socioculturais da internet no Brasil. 28-29, ago. 1995. Disponível em: <http://www.alternex.com.br/ esocius/t-tamara.html> Acesso em: 09/11/2004.

CASTELLS, Manuel. A sociedade em rede. São Paulo: Paz e Terra, 1999.

CEBRIÁN, Juan Luis. A rede: como nossas vidas serão transformadas pelos novos meios de comunicação. Tradução de Lauro Machado Coelho. São Paulo: Summus, 1999. (Coleção novas buscas de comunicação, v. 59).

DORON, Roland e PAROT, Françoise. Dicionário de psicologia. Tradução de Odilon Soares Leme. São Paulo: Ática, 2001.

FERREIRA, Aurélio Buarque de Holanda. Novo Aurélio Século XXI: o dicionário da língua portuguesa. $3^{\text {a }}$ ed. Rio de Janeiro: Nova Fronteira, 1999.

FORQUIM, Jean-Claude. Escola e Cultura: as bases sociais e epistemológicas do conhecimento escolar. Porto Alegre: Artes Médicas, 1993.

FREITAS, Jackeline Spinola de. A cultura técnica e o uso das novas tecnologias de informação. Disponível em: <http://www.intercom.org.br/papers/viii-sipec/gt09/80jackelinecompleto.htm> Acesso em: 20/10/2004.

GOHN, Maria da Glória. Educação não-formal e cultura política: impactos sobre o associativismo do terceiro setor. $2^{\mathrm{a}}$ ed. São Paulo: Cortez, 2001. (Coleção Questões da nossa época, v. 71).

GRAELLS, Pere Marquès. La cultura tecnológica en la sociedad de la información. Departamento de Pedagogia Aplicada, Facultad de Educación, UAB, Espanha, 2000. Disponível em: <http://dewey.uab.es/pmarques/si.htm> Acesso em: 18/11/2004.

KENSKI, Vani Moreira. Tecnologias e ensino presencial e a distância. Campinas, SP: Papirus, 2003.

LARAIA, Roque de Barros. Cultura: um conceito antropológico. 14ª ed. Rio de Janeiro: Jorge Zahar Editor, 2001.

LEMOS, André. Cibercidades: um modelo de inteligência coletiva. In: LEMOS, André (Org). Cibercidade: as cidades na cibercultura. Rio de Janeiro: E-papers Serviços Editoriais, 2004, p. 19-26.

LEMOS, André. Les communautes virtuelles. In: Sociétés, n. 45, Ed. Dunod, Paris, 1994. Disponível em: <http://www.facom.ufba.br/pesq/cyber/lemos/cvirtual.html> Acesso em: 09/11/2004.

LÉVY, Pierre. Cibercultura. Tradução de Carlos Irineu as Costa. São Paulo: Editora 34, 1999. 
MORAN, José Manuel. Ensino e aprendizagem inovadores com tecnologia audiovisuais telemáticas. In: MORAN, José Manuel e outros. Novas tecnologias e mediação pedagógica. Campinas, SP: Papirus. 2000, p. 11-65. (Coleção Papirus Educação).

PENIN, Sônia Teresinha de Souza. Progestão: como articular a função social da escola com as especificidades e as demandas da comunidade? Módulo I / Sônia Teresinha de Sousa Penin, Sofia Lerche Vieira; Coordenação Geral: Maria Aglaê de Medeiros Machado. Brasília: CONSED - Conselho Nacional de Secretários de Educação, 2001.

REDÁ, Amanda, ALVES, Patrícia Ferreira e TONANI Renata. Projeto de Pesquisa Cultura Tecnológica. Belo Horizonte: CEFET-MG, 2006. (Trabalho apresentado na disciplina "Educação e Cultura em Ciência e Tecnologia", do Mestrado em Educação Tecnológica).

RODRIGUES, Anna Maria Moog. Por uma filosofia da tecnologia. In: GRINSPUN, Mirian P. S. Zippin (Org). Educação tecnológica: desafios e perspectivas. $2^{a}$ ed. São Paulo: Cortez, 2001, p. 75-129.

SAMPAIO, Marisa Narcizo e LEITE, Lígia Silva. Alfabetização tecnológica do professor. $2^{\text {a }}$ ed. Petrópolis: Vozes, 1999.

SANTOS, José Luiz dos. O que é cultura. 16a edição. São Paulo: Brasiliense, 1996. (Coleção Primeiros Passos, n. 110).

SCHLITHLER, Célia Regina Belizia. O processo de formação de facilitadores de redes sociais. Atualizado em 01/04/2003. Disponível em: <http://www.rits.org.br/redes_teste/rd_tmes_fev2003.cfm> Acesso em: 27/11/2004.

VALENTE, José Armando. A espiral da aprendizagem e as tecnologias da informação e comunicação: repensando conceitos. In: JOLY, Maria Cristina Rodrigues Azevedo (Org). A tecnologia no ensino: implicações para a aprendizagem. São Paulo: Casa do Psicólogo, 2002.

i O que não significa que conhecimento e informação sejam sinônimos.

ii Ver Santos (1996) e Gohn (2001).

iii Ver Santos (1996) e Gohn (2001).

iv Ver Santos (1996).

v Ver Gohn (2001).

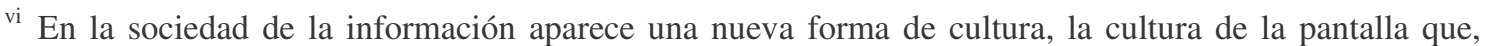
como decía Arenas (1991), se superpone a la cultura del contacto personal y la cultura del libro. Además, junto al entorno físico, real, con el que interactuamos, ahora disponemos también del ciberespacio, entorno virtual, que multiplica y facilita nuestras posibilidades de acceso a la información y de comunicación con los demás (GRAELLS, 2000, p. 4).

vii Par cyberculture on comprend l'ensemble d'attitudes (appropriation, détournement, activisme), nés à partir du mariage entre les technologies informatiques et les médias de communication. Cet ensemble d'attitudes est produit d'un mouvement socioculturel pour apprivoiser et "humaniser" les nouvelles technologies. Selon mon hypothèse, elle est l'expression culturelle de la rencontre entre la "socialité post moderne" et les nouvelles technologies basées sur la micro-électronique. (LEMOS, 1994, p. 1).

viii Com o intuito de preservar a identidade dos informantes, os depoimentos são identificados pelos códigos GGX e E-XXX, onde X representa um número sequiencial. Os depoimentos identificados com 
GGX são dos componentes do Grupo Gestor, e os identificados com E-XXX, são dos educadores que responderam ao questionário.

${ }^{\text {ix }}$ Professor Orientador de Informática Educativa.

DATA RECEBIMENTO: 16/01/2007

DATA APROVAÇÃO: 20/08/2007 